\title{
Pyrolytic Recycling of Carbon Fibers from Prepregs and Their Use in Polyamide Composites
}

\author{
Stephan Schwarz ${ }^{1}$, Thomas Höftberger ${ }^{2}$, Christoph Burgstaller ${ }^{2}$, \\ Andreas Hackl ${ }^{3}$, Clemens Schwarzinger ${ }^{1}$ \\ ${ }^{1}$ Institute for Chemical Technology of Organic Materials, Johannes Kepler University, Linz, Austria \\ ${ }^{2}$ Transfercenter für Kunststoffetechnik, Wels, Austria \\ ${ }^{3}$ Next Generation Elements, Feldkirchen, Austria \\ Email: clemens.schwarzinger@jku.at
}

How to cite this paper: Schwarz, S., Höftberger, T., Burgstaller, C., Hackl, A. and Schwarzinger, C. (2020) Pyrolytic Recycling of Carbon Fibers from Prepregs and Their Use in Polyamide Composites. Open Journal of Composite Materials, 10, 92-105. https://doi.org/10.4236/ojcm.2020.104007

Received: June 27, 2020

Accepted: August 7, 2020

Published: August 10, 2020

Copyright $\odot 2020$ by author(s) and Scientific Research Publishing Inc. This work is licensed under the Creative Commons Attribution International License (CC BY 4.0)

http://creativecommons.org/licenses/by/4.0/

\begin{abstract}
Carbon fibers composites are well-known as high tech materials but are also recognized as a problem after use as they have to be deposited in landfills. Pyrolysis is an attractive process for recycling carbon fibers from used composites as well as offcuts from prepregs. Pyrolysis of carbon fiber composite prepregs is carried out in a pilot plant with a single screw reactor. The pyrolysis products, carbon fibers and pyrolysis vapor are fully characterized. Variation of pyrolysis temperature is carried out to obtain carbon fibers with the best possible surface properties. In order to compare the mechanical properties of the recycled carbon fibers with virgin material, composite materials with polyamide are produced and their properties compared.
\end{abstract}

\section{Keywords}

Carbon Fibers Composites, Mechanical Properties

\section{Introduction}

Carbon fiber composites (CFC) consist of carbon fibers and a polymer matrix, the matrix consists mostly of a thermoset [1]. If the CFC is to be recycled, the two phases must be separated from each other [2]. Due to its good mechanical properties and low weight, CFC is increasingly being used [1] [3], for example in cars, aviation, sports and military applications [4] [5]. About 25\% of an Airbus or Boeing aircraft consists of CFC [6]. The global demand for carbon fibers is estimated to be 140,000 tons in 2020 [7]. 
At the end of their product life, carbon fiber products must be recycled or disposed of in landfills [4]. When recycling CFC, there are the possibilities of mechanical, chemical and thermal processes. In the mechanical process, the feedstock is merely ground and the product has to be used in low-value applications as a filler [3] [5]. In the chemical process, the resin is degraded by various solvents and converted into a soluble form, thus the carbon fibers can be recovered. In pyrolysis, which is a thermal process, the resin matrix is broken down into smaller volatile molecules and the carbon fibers remain intact [5] [8].

After the recycling process, the question remains how such recycled carbon fibers can be used. As they are not long filaments anymore, application in fabrics is limited. Hengstermann [9] investigated the possibilities of spinning hybrid yarns from PA6 and short carbon fibers as a possible process route to use recycled carbon fibres (rCF) in fabrics again. Another approach is to use $\mathrm{rCF}$ as a substitute for short carbon fibers in polymer matrix composites, i.e. as the reinforcement in the matrix. Here, investigations on how to improve the interaction between the fiber and the matrix [10] have been carried out by surface treatment. Also, some initial investigations were carried out to investigate $\mathrm{rCF}$ performance in polymer matrix composites [11]. These rCF were supplied by SGL and are supposedly cut-offs from dry fibers. In our study, we wanted to use fibers after recycling through pyrolysis, as this will also have an influence on the fiber surface which influences the interaction between the fibers and the matrix.

The aim of the present work is: 1) The recovery of clean carbon fibers from waste CFC prepregs, 2) the optimization of pyrolysis temperature and the characterization of carbon fibers and pyrolysis vapor, and 3) to investigate the reinforcing potential of such recycled carbon fibers ( $\mathrm{rCF}$ ) compared to virgin chopped carbon fibers (vCF).

\section{Results and Discussion}

As feedstock for pyrolysis uncured carbon fiber composite (CFC) prepreg cut-offs with a protecting film of polyethylene (PE) in pelletized form is used. The carbon fiber composite is from production waste, which was impregnated with uncured epoxy resin. In Table 1 the analysis of the feedstock is shown, the high sulfur content $(0.3 \%)$ relates to a sulfur-containing cross-linker in the epoxy resin.

The pyrolysis was been done in a single screw pyrolysis reactor, as described in the experimental part. The experimental parameters used for pyrolysis are described in Table 2. The residence time was fixed at $30 \mathrm{~min}$ and the pyrolysis temperature was varied between $480^{\circ} \mathrm{C}$ and $560^{\circ} \mathrm{C}$. The solid pyrolysis residue decreased with increasing reaction temperature.

The heat of gasification describes the overall heat that is needed to pyrolyze one $\mathrm{kg}$ of input material starting from room temperature. In Table 3 it can be seen that with increasing pyrolysis temperature the heat of gasification also increases. The lower heating value of the pyrolysis vapors rises with increasing reaction temperature. 
Table 1. Analysis of the feedstock and the pyrolysis residues.

\begin{tabular}{|c|c|c|c|c|}
\hline & \multirow{2}{*}{ feedstock } & \multicolumn{3}{|c|}{ Pyrolysis Temperature $\left({ }^{\circ} \mathrm{C}\right)$} \\
\hline & & 480 & 520 & 560 \\
\hline \multicolumn{5}{|c|}{ Proximate Analysis (wt\%) } \\
\hline Moisture & 5.1 & n.m. & n.m. & n.m. \\
\hline $\operatorname{Ash}^{\mathrm{dm}}$ & 2.6 & 6.4 & 5.1 & 7.3 \\
\hline \multicolumn{5}{|c|}{ Energy $\left(\mathrm{MJ} \cdot \mathrm{kg}^{-1}\right)$} \\
\hline $\mathrm{LHV}^{\mathrm{dm}}$ & 26.9 & 31.4 & 31.1 & 31.7 \\
\hline \multicolumn{5}{|c|}{ Ultimate Analysis (wt\%) ${ }^{\mathrm{dm}}$} \\
\hline $\mathrm{C}$ & 65.8 & 86.0 & 86.4 & 87.4 \\
\hline $\mathrm{H}$ & 6.3 & 1.7 & 1.2 & 1.0 \\
\hline S & 0.3 & n.d. & n.d. & n.d. \\
\hline \multicolumn{5}{|c|}{ Metals $\left(\mathrm{mg} \cdot \mathrm{kg}^{-1}\right)^{\mathrm{dm}}$} \\
\hline $\mathrm{Na}$ & 71 & 250 & 167 & 353 \\
\hline $\mathrm{Mg}$ & 269 & 700 & 619 & 908 \\
\hline $\mathrm{Al}$ & 648 & 1605 & 1442 & 2242 \\
\hline $\mathrm{K}$ & 20 & 137 & 126 & 242 \\
\hline $\mathrm{Ca}$ & 64 & 109 & 99 & 129 \\
\hline $\mathrm{V}$ & 1 & 2 & 2 & 2 \\
\hline $\mathrm{Cr}$ & 4 & 16 & 10 & 21 \\
\hline $\mathrm{Mn}$ & 8 & 17 & 11 & 35 \\
\hline $\mathrm{Fe}$ & 181 & 1030 & 617 & 1644 \\
\hline Co & n.d. & 1 & n.d. & 1 \\
\hline $\mathrm{Ni}$ & 1 & 6 & 3 & 12 \\
\hline $\mathrm{Cu}$ & 76 & 393 & 380 & 146 \\
\hline $\mathrm{Zn}$ & 3 & 6 & 9 & 11 \\
\hline $\mathrm{Pb}$ & n.d. & 1 & 1 & 2 \\
\hline
\end{tabular}

dm: dry matter, n.d.: not detected, n.m.: not measured, LHV: lower heating value.

Table 2. Experimental data of the pyrolysis experiments.

\begin{tabular}{cccc}
\hline Temperature $\left({ }^{\circ} \mathrm{C}\right)$ & 480 & 520 & 560 \\
Residence time $(\mathrm{min})$ & 30 & 30 & 30 \\
Duration $(\mathrm{h})$ & 1.5 & 0.5 & 0.5 \\
Mass flow $\left(\mathrm{kg} \cdot \mathrm{h}^{-1}\right)$ & 12.0 & 9.5 & 4.8 \\
Total mass input $(\mathrm{kg})$ & 18.0 & 4.8 & 1.5 \\
Mass solid residue $(\mathrm{kg})$ & 6.1 & 1.6 & 32.0 \\
Solid residue $(\mathrm{wt} \%)$ & 34.0 & 33.0 & \\
\hline
\end{tabular}


Table 3. Heat of gasification and lower heating value of the pyrolysis vapor.

\begin{tabular}{cccc}
\hline Temperature $\left({ }^{\circ} \mathrm{C}\right)$ & 480 & 520 & 560 \\
Heat of Gasification $\left(\mathrm{MJ} \cdot \mathrm{kg}^{-1}\right)$ & 0.9 & 1.1 & 1.6 \\
LHV pyrolysis vapour $\left(\mathrm{MJ} \cdot \mathrm{kg}^{-1}\right)$ & 22.0 & 24.8 & 26.3 \\
\hline
\end{tabular}

Table 4. Compounds identified with Py-GC/MS @ 550 ${ }^{\circ} \mathrm{C}$ in the CFC prepreg.

\begin{tabular}{ccc}
\hline Peak no. & Retention time $(\mathrm{min})$ & Identified species \\
\hline 1 & 1.47 & Carbon dioxide \\
2 & 1.64 & 2 -Propanone \\
3 & 1.73 & 2 -Propen-1-ol \\
4 & 5.35 & Phenol \\
5 & 6.00 & $o$-Cresol \\
6 & 6.16 & $p$-Cresol \\
7 & 7.14 & $o$-Allylphenol \\
8 & 7.33 & $p$-Isopropylphenol \\
9 & 8.00 & $p$-Isopropenylphenol \\
10 & 9.30 & 3,5 -Dichloroaniline \\
11 & 12.73 & $p$-(p-Hydroxybenzyl)phenol \\
12 & 13.54 & Bisphenol A \\
\hline
\end{tabular}

Table 4 lists the compounds that could be identified with pyrolysis-gas chromatography-mass spectrometry (Py-GC-MS). The sample used for analysis was the CFC prepreg without PE protective film, therefore the PE fragments are missing in the pyrogram (compare Figure 1 and Figure 2). In analytical pyrolysis, the resin component bisphenol A could be detected (Table 4), which could not be detected in the pyrolysis vapor from the plant (Table 5). This can be explained by the thermolysis on the hot reactor wall of bisphenol A to $p$-isopropylphenol and phenol (Table 5). The origin of dichloro aniline is yet undetermined.

The compounds formed during pyrolysis of CFC prepregs at all temperatures in the screw reactor are listed in Table 5, the pyrolysis products of PE (alkanes, alkenes, and alkadienes) have been omitted for clarity. The chromatogram obtained at $480^{\circ} \mathrm{C}$ is shown in Figure 2. The numerous sharp peaks correlate to the PE pyrolysis products, additionally, the vapor consists mainly of phenols and aromatics. The primary pyrolysis products of $\mathrm{PE}$ are the hydrocarbons alkanes, alkenes, and alkadienes and could be detected up to $\mathrm{C}_{29}$. The aromatics are formed by secondary reactions such as cyclization and aromatization from the PE fragments by secondary pyrolysis reactions.

Table 1 summarizes the results of pyrolysis cokes analyses. With increasing pyrolysis temperature, the carbon content increases from $86.0 \%$ to $87.4 \%$, while the hydrogen content decreases by $0.7 \%$ down to $1.0 \%$. These data suggest incomplete 


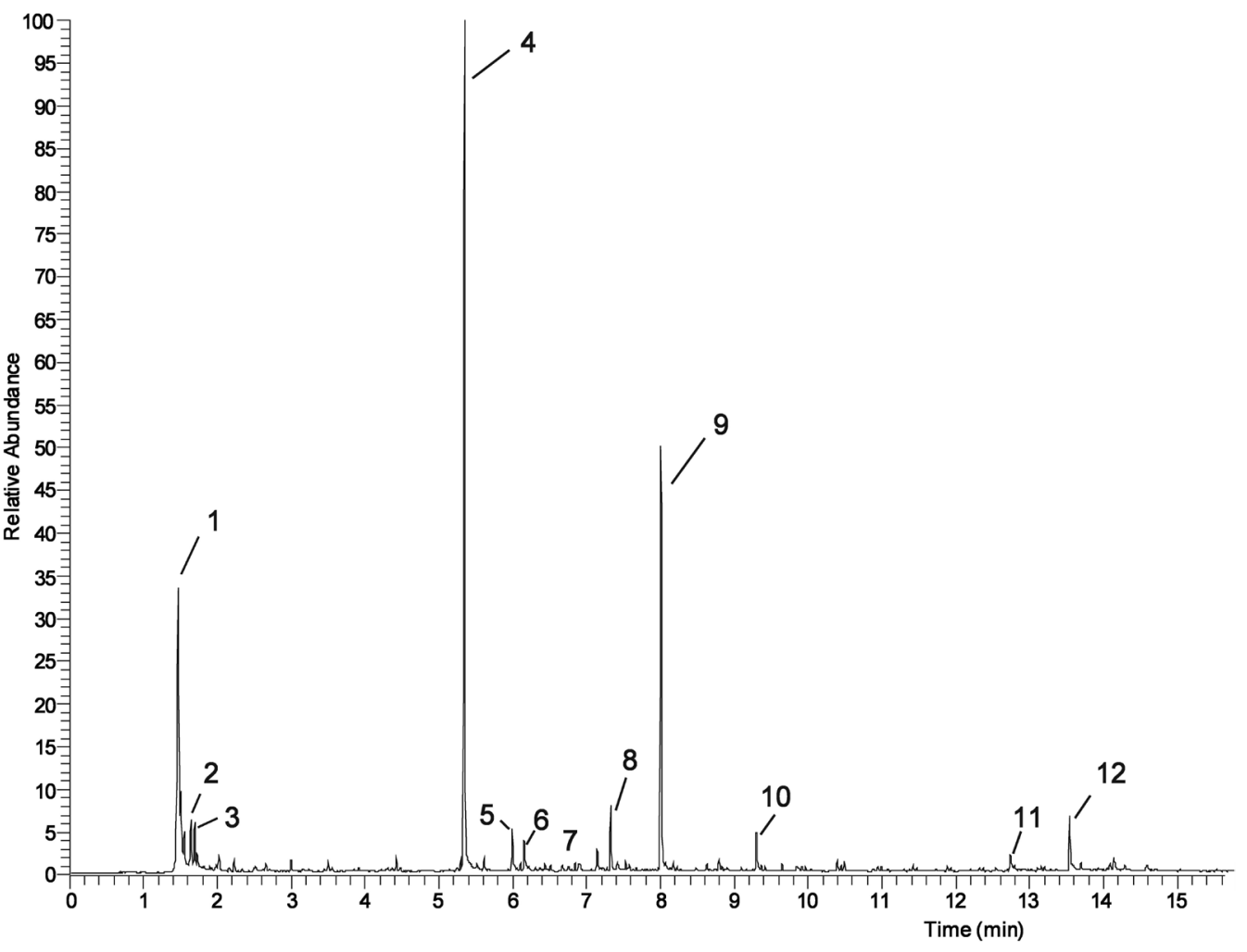

Figure 1. Pyrogramm of the CFC prepreg @ 550 ${ }^{\circ} \mathrm{C}$.

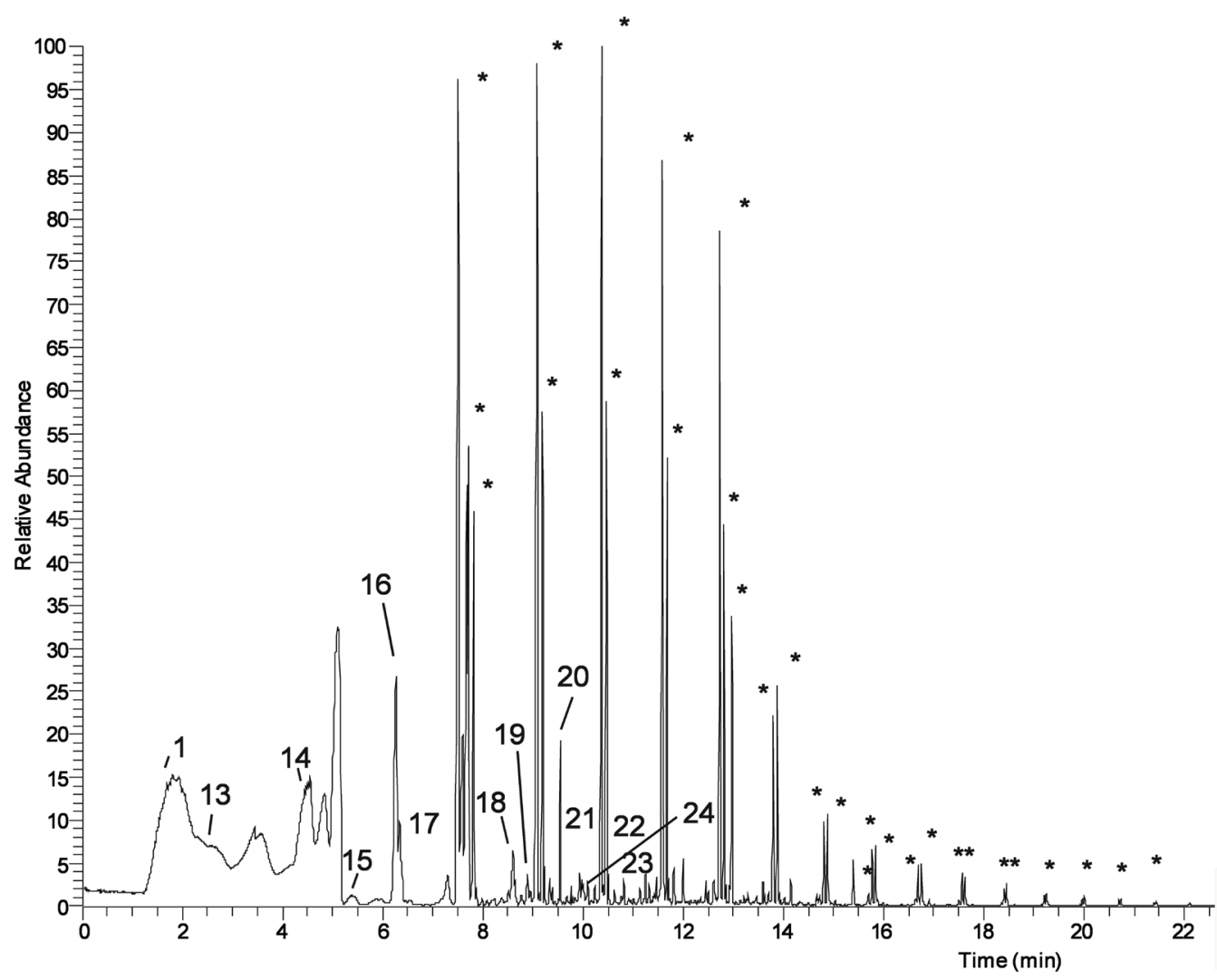

Figure 2. GC-MS of the CFC preprep pyrolysis vapours @ $480^{\circ} \mathrm{C}$, peaks marked with an asterisk are derived from PE. 
Table 5. Compounds identified with GC-MS in the pyrolysis vapor.

\begin{tabular}{|c|c|c|}
\hline Peak no & Retention time (min) & Identified species \\
\hline 1 & 1.80 & Carbon dioxide \\
\hline 13 & 2.90 & Benzene \\
\hline 14 & 4.55 & Toluene \\
\hline 15 & 5.88 & Ethylbenzene \\
\hline 16 & 6.28 & Xylene \\
\hline 17 & 7.60 & Phenol \\
\hline 18 & 8.60 & $o$-Cresol \\
\hline 19 & 8.89 & $p$-Cresol \\
\hline 20 & 9.63 & $o$-Ethylphenol \\
\hline 21 & 9.83 & Xylenol \\
\hline 22 & 9.93 & 1,2-Dihydronaphthalene \\
\hline 23 & 9.98 & Pentylbenzene \\
\hline 24 & 10.09 & 2-Phenylpentane \\
\hline 25 & 10.47 & Naphthalene \\
\hline 26 & 10.82 & p-Isopropylphenol \\
\hline 27 & 11.25 & Hexylbenzene \\
\hline 28 & 11.32 & 2-Phenylhexane \\
\hline 29 & 11.81 & 2-Methylnaphthalene \\
\hline 30 & 12.01 & 1-Methylnaphthalene \\
\hline 31 & 12.46 & Heptylbenzene \\
\hline 32 & 12.98 & Diphenyl ether \\
\hline 33 & 14.14 & $p$-Phenoxytoluene \\
\hline 34 & 15.68 & Decylbenzene \\
\hline 35 & 16.65 & Undecylbenzene \\
\hline 36 & 16.91 & 9-Methylene-fluorene \\
\hline 37 & 20.06 & Pentadecylbenzene \\
\hline
\end{tabular}

pyrolysis at low temperatures. The sulfur content is significantly reduced compared to the starting material, which indicates the use of sulfur-containing cross-linker in the resin matrix.

In Figure 3 the scanning electron microscope (SEM) images of the recycled carbon fibers are shown. It can be seen that the carbon fiber surface has not suffered any noticeable damage from the pyrolysis process. The small dots on the surface of the fibers originate from the pyrolysis coke of the resin. By increasing the pyrolysis temperature, carbon fibers with fewer impurities on the surface are obtained. The experiment at $480^{\circ} \mathrm{C}$ pyrolysis temperature yields carbon fibers with a large number of particles on the surface (Figure 3), presumably due to not completely pyrolyzed resin matrix. 

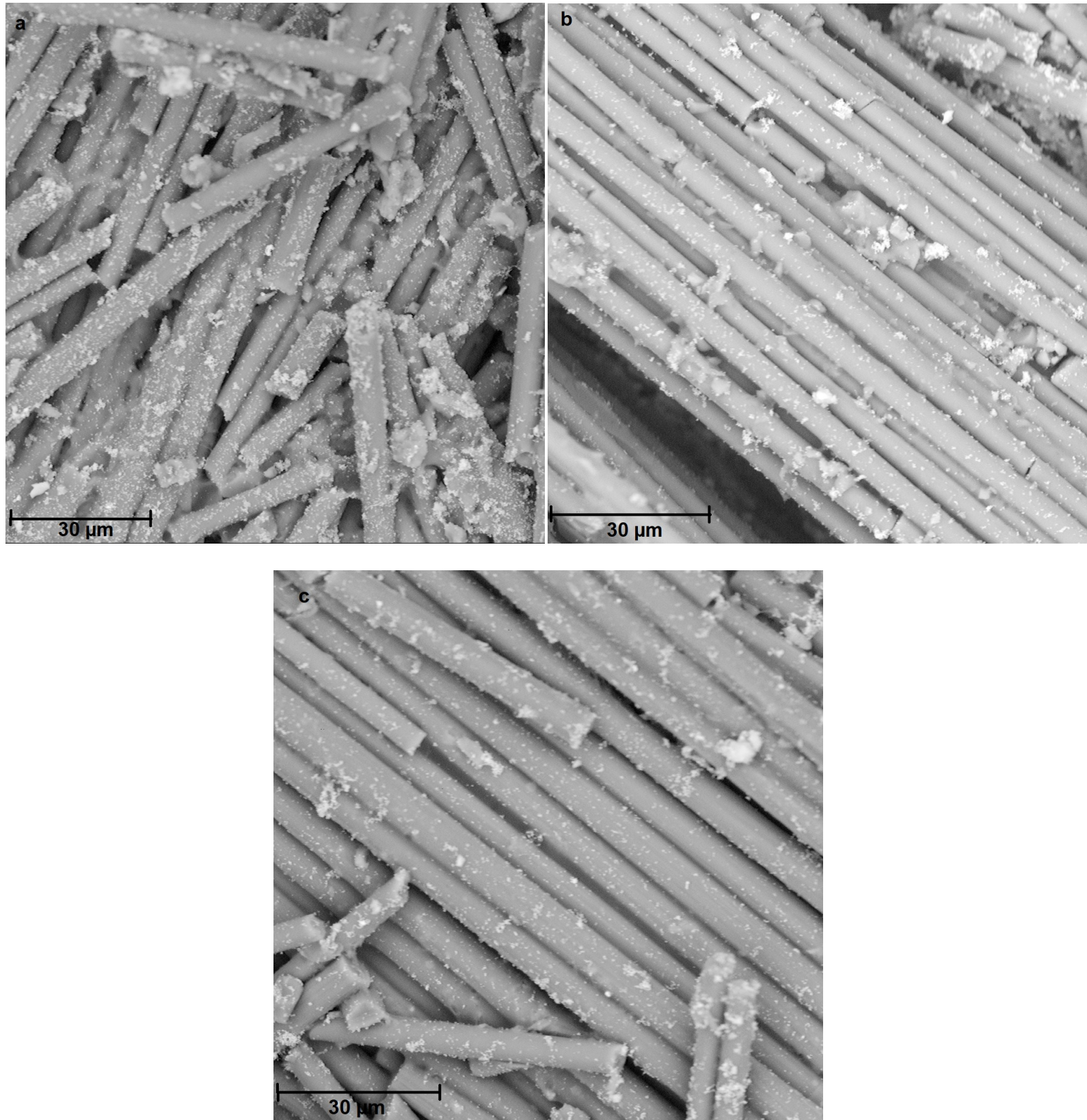

Figure 3. SEM images of carbon fibers after pyrolysis. (a) $480^{\circ} \mathrm{C}$, (b) $520^{\circ} \mathrm{C}$, (c) $560^{\circ} \mathrm{C}$.

To investigate the reinforcing potential of the fibers, the mixed carbon fibers from the different pyrolysis temperatures were used to produce a polymer matrix composite with $30 \mathrm{wt} \%$ of the different carbon fibers in polyamide 6 . As the $\mathrm{rCF}$ exhibit some moisture, a portion of these were dried ( $\mathrm{rCFd}$ ) to improve the flowability in the compounding process. Moist rCF are sticking to the walls and screws of the dosing unit, and this is the reason for process instabilities, as the $\mathrm{rCF}$ are not fed at a constant rate into the extruder for compounding. This is more of a critical issue in bigger extruders than we used for this study, as there are higher throughputs to realize, but we wanted to see if there are any effects on the $\mathrm{rCF}$ in the composite with drying. For comparison, also virgin carbon fibers 
(vCF) were used. As shown in Figure 4, the rCF exhibit lower properties than the vCF. Elastic modulus and tensile strength are below $50 \%$ of the values of the $\mathrm{vCF}$. Also the notched impact strength is significantly lower. Usually, this would be attributed to the fiber length, as this is the dominant factor in regard to the mechanical properties. Here, the fiber lengths are somewhat similar (between $380 \mu \mathrm{m}$ for vCF and $340 \mu \mathrm{m}$ for $\mathrm{rCF}$ ), so this does not explain such big differences. As the average value for the fiber length can be deceptive, we also evaluated the fiber length distribution of the three different composites (Figure 5). From this one can see that the $\mathrm{rCF}$ and $\mathrm{rCFd}$ exhibit more fibers at lower lengths, but the differences here also do not explain the extent of the difference in mechanical properties. The other determining factor for the mechanical properties of a composite is the interaction between the fibers and the matrix [12]. This is facilitated by fiber surface treatments, which can interact with both the fiber and the matrix, therefore enabling load transfer via the interface and reinforcing the matrix. As the $\mathrm{rCF}$ and $\mathrm{rCFd}$ are pyrolyzed, the fiber surface treatment will also be affected by that, at least partially, which leads to reduced reinforcing capabilities and therefore reduced mechanical properties. The difference in mechanical properties between $\mathrm{rCF}$ and $\mathrm{rCFd}$ can also be explained by the interaction at the interface as the main factor. With the drying step, moisture is evaporated off the fibers, but also other volatiles are extracted, which again reduces the fiber surface treatment and thus the mechanical properties. Another factor, which has to be taken into account here is that the input material is from production waste, and therefore also some uncertainty is introduced in the material, which also influences the composite properties.

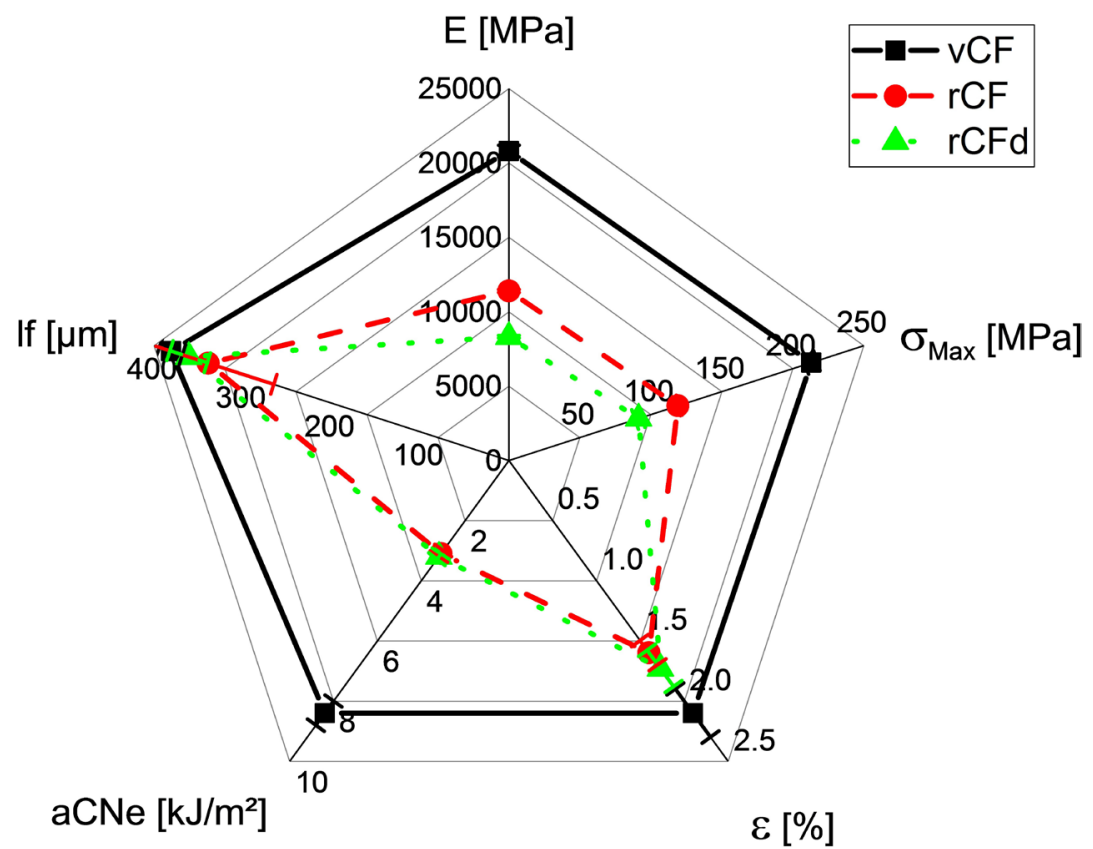

Figure 4. Mechanical properties and fibre length of the composites with different $\mathrm{CF}$ in PA6 ( $E \ldots$ elastic modulus, $\sigma_{\operatorname{Max}} \ldots$ tensile strength, $\varepsilon \ldots$ strain at yield, $a_{C N e} \ldots$ notched Charpy impact strength, If ... average fiber length). 


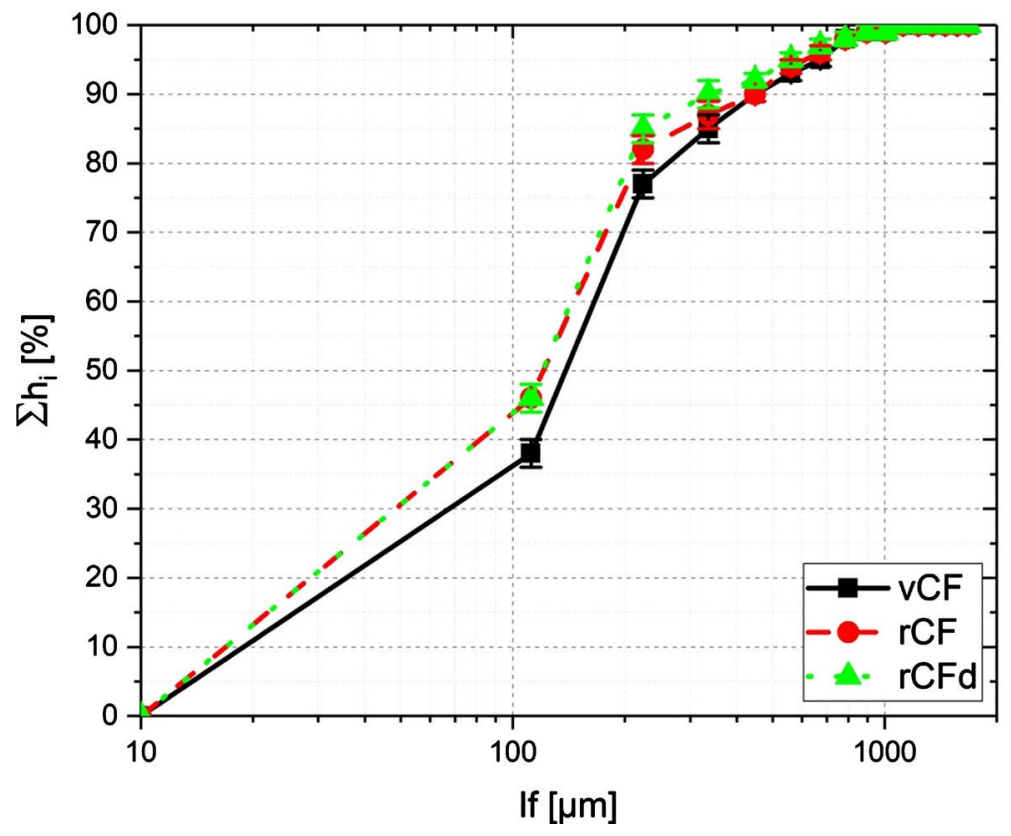

Figure 5. Fiber length distribution of the fibers extracted from the different composites (fiber lengths below $110 \mu \mathrm{m}$ are not given individually as a limitation of measuring capacity).

\section{Experimental}

The uncured prepregs (production cut-offs) were supplied by a company working in aviation industry. These are pyrolyzed to yield rCF. Part of the rCF was packed in a filter bag and dried in a hot air cabinet at $120^{\circ} \mathrm{C}$ to remove moisture (rCFd). Chopped carbon fiber (Zoltek PX35CF0333) were used as reference virgin carbon fibers $(\mathrm{vCF})$. As the matrix for composite production, polyamide 6 (Durethan B30S, Lanxess, Germany) was used.

For the determination of the heating value and elemental composition the samples were ground cryogenically with a Spex Sample Prep Freezer Mill 6770.

Heating value:

The heating values of the samples were measured with a bomb calorimeter.

Elemental analysis:

The content of $\mathrm{C}, \mathrm{H}$ and $\mathrm{S}$ was detected with the addition of $\mathrm{V}_{2} \mathrm{O}_{5}$ in a Thermo Electron Corporation Flash EA 1112 Series apparatus.

Ash content:

The amount of ash in the samples was measured with a CEM Phoenix microwave oven at $1000^{\circ} \mathrm{C}$.

Microwave digestion:

For measuring the samples with ICP-MS they were dissolved with the help of a CEM Mars 6 microwave. $0.1 \mathrm{~g}$ sample was heated in $10 \mathrm{~mL}$ nitric acid for 20 minutes at $200^{\circ} \mathrm{C}$. In a second step, $3 \mathrm{~mL}$ of hydrochloric acid were added, and the sample was reheated to $200^{\circ} \mathrm{C}$ for another 15 minutes.

ICP-MS Measurement:

The ICP-MS analysis was done with a Thermo X Series 2 device. The parame- 
ters used for analysis are listed in Table 6.

For calibration a multi-element standard with 30 elements from Merck was used. The device was calibrated in the range of $1-1000 \mathrm{ppb}$.

Pyrolysis-GC-MS

Pyrolysis experiments were carried out with a CDS Pyroprobe 5250 pyrolyzer (CDS Analytical Inc.). The pyrolyzer is coupled to a Trace GC Ultra (Thermo Electron Corp.) equipped with a capillary column Restek RTX35 (30 m × 0.32 $\mathrm{mm} \times 0.25 \mu \mathrm{m}$ ), and a quadrupole mass spectrometer MD 800 (Fisons Instruments). Pyrolysis was performed at $550^{\circ} \mathrm{C}$ for $10 \mathrm{~s}$. The pyrolyzer interface was set at $300^{\circ} \mathrm{C}$ and the injector at $280^{\circ} \mathrm{C}$. The GC column temperature conditions were as follows: initial temperature $50^{\circ} \mathrm{C}$, hold for $2 \mathrm{~min}$, increase at $20^{\circ} \mathrm{C} \cdot \mathrm{min}^{-1}$ to $300^{\circ} \mathrm{C}$, and hold this temperature for $10 \mathrm{~min}$. Helium gas flow was set to 1.5 $\mathrm{mL} \cdot \mathrm{min}^{-1}$, the split flow was $45 \mathrm{~mL} \cdot \mathrm{min}^{-1}$. Mass spectra were recorded with electron impact ionization at $70 \mathrm{eV}$ electron energy in the range from $\mathrm{m} / z 15$ to 400 .

GC-MS analysis on pilot plant

The pyrolysis gas is sent from the pyrolysis reactor to the GC via a heated pipe held at $300^{\circ} \mathrm{C}$. To clean the pyrolysis gas from coke particles and high boiling tar it is sent through a heated settling vessel and a hot gas filter.

The pyrolysis gas from the plant is transferred to the GC with a valved Interface 1500 (CDS) kept at $300^{\circ} \mathrm{C}$. A Trace GC (Thermo Electron Corp.) equipped with a capillary column Restek Rxi-5Sil MS $(30 \mathrm{~m} \times 0.25 \mathrm{~mm} \times 0.50 \mu \mathrm{m})$, and a quadrupole mass spectrometer MD 800 (Fisons Instruments) is used for gas analysis. The GC column temperature conditions were the same that were used for pyrolysis-GC-MS.

Mass spectra were recorded with electron impact ionization at $70 \mathrm{eV}$ electron energy in the range from $\mathrm{m} / z 35$ to 435 .

The pilot plant unit

In Figure 6 the design of the pilot plant is shown. For the inert supply of material a feeding system (1) was used. It consists of a vibrating plate and a double

Table 6. ICP/MS parameters.

\begin{tabular}{cc}
\hline parameter & value \\
\hline RF power (W) & 1400 \\
Extraction (V) & -196 \\
Lens 1 (V) & -1100 \\
Lens 2 (V) & -113 \\
Focus (V) & 13 \\
Pole Bias (V) & -3 \\
Hexapole Bias (V) & -4 \\
Nebuliser gas flow (ml-min $\left.{ }^{-1}\right)$ & 0.8 \\
Plasma gas & Argon 5.0 \\
Sprayer & Mira Mist
\end{tabular}




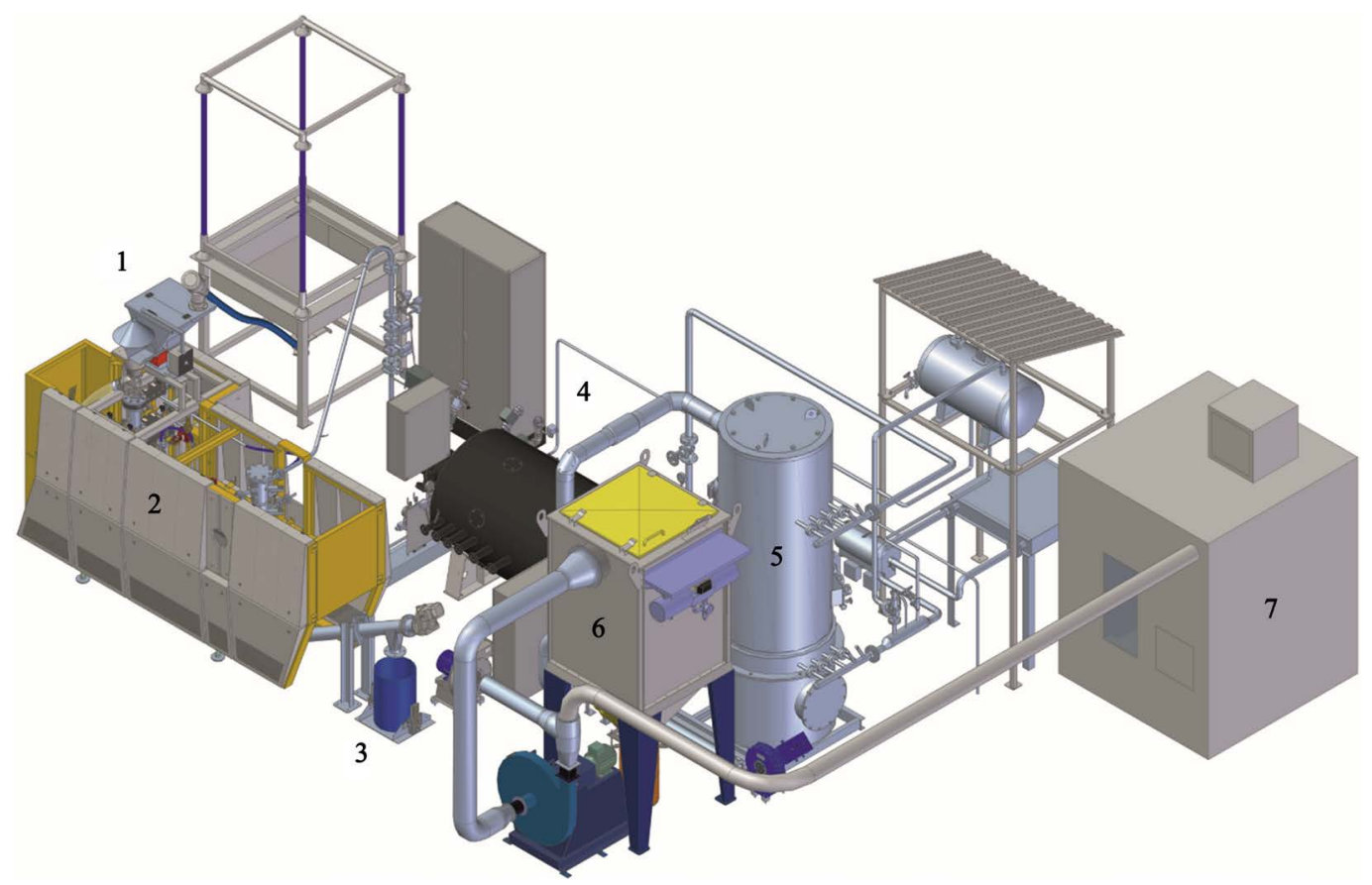

Figure 6. Parts of the pilot plant (designed with solid edge software). Numbers refer to description in the text.

valved vessel for inert feeding of the material into the reactor. The pyrolysis unit (2) is manufactured as a single screw reactor. The reactor is heated electrically with six heating tapes and a heating cartridge in the screw. The pyrolysis screw has a length of $2400 \mathrm{~mm}$, and a diameter of $180 \mathrm{~mm}$ and 13 screw windings. To exclude oxygen from the pyrolysis reaction the pyrolysis system is purged with nitrogen. With the reactor system it is possible to reach pyrolysis temperatures of up to $560^{\circ} \mathrm{C}$ and residence times between 7 and 40 minutes. The pyrolysis residue is transferred via the outlet (3) into a steel bin. The pyrolysis vapor is routed through a heated pipe to the burner. The offgas from the burner is cooled in a heat exchanger (5). Afterwards the offgas is cleaned in a flue gas filter (6) and guided through an alkaline scrubber (7) to remove acidic components, like $\mathrm{HCl}$ and sulfur dioxide.

Determination of the Heat of Gasification:

For the measurement of the heat of gasification, the electrical power consumption of the reactor heating was summed up and related to the mass of the feedstock. The heat losses of the reactor were determined by an idling cycle and deducted.

Measurement of the lower heating value of the pyrolysis vapor:

The pyrolysis gas calorific value was determined by the energy balance of the thermal oil boiler. For this purpose, the amount of heat was measured by the temperature difference between thermal oil flow and return. The thermal oil flow was measured by a flowmeter. The heat losses of the thermal oil boiler were determined by a test run with propane and taken into account in the calculation of the pyrolysis gas calorific value. 


\section{Composite production:}

Composites containing $30 \mathrm{wt} \%$ of the different carbon fibers were produced by means of a co-rotating twin screw extruder (Thermo Prism TSE24MC, Thermo Fisher, Germany) with a processing length of $40 \mathrm{~L} / \mathrm{D}$. The PA6 is dosed into the intake (barrel section one), and the carbon fibers are dosed into the machine via a side-feeder into barrel section eight out of ten. The maximum barrel temperature was set to $280^{\circ} \mathrm{C}$ and the throughput was $8 \mathrm{~kg} / \mathrm{h}$. The PA6 was pre-dried at $80^{\circ} \mathrm{C}$ for at least four hours in a dry-air drier. The extruded melt strands were cooled in a water bath, cut to granules and moulded into universal test specimen (according to ISO-527) with a conventional injection moulding machine (Victory 80, Engel, Austria) with a maximum melt temperature of $280^{\circ} \mathrm{C}$. All three formulations were treated the same in processing to ensure comparable results.

Composite testing

Tensile properties (ISO 527) were tested on universal test specimens (type 1A) at a universal testing machine (20 kN load cell, Zwick Roell, Germany) with a crosshead speed of $1 \mathrm{~mm} / \mathrm{min}$ for determining the elastic modulus and 5 $\mathrm{mm} / \mathrm{min}$ until the break of the samples, where tensile strength and yield strain were recorded. For each sample, five replicates were tested. Notched Charpy impact strength was tested with a pendulum impactor (5113.300, Zwick Roell, Germany) after punching out the parallel parts from the universal test specimens and notching these with a precision circular saw (Diadisc, Mutronic, Germany) equipped with a saw blade with the specific notch shape. Ten replicates were measured per sample.

To determine the fiber length, $1 \mathrm{~g}$ of the composite samples were ashed in a crucible in a muffle furnace at $500^{\circ} \mathrm{C}$ for $2 \mathrm{~h}$. The yielded carbon fibres then are dispersed in water at a concentration of $0.018 \mathrm{~g} / \mathrm{l}$ with some droplets of glycerol added to aid fiber wetting. Approximately $10 \mathrm{ml}$ of the solution was filled into a petri-dish, the water was evaporated in a hot air cabinet and the petri dish was then scanned by a flatbed-scanner to generate pictures for fiber length evaluation. This was carried out by software (Fasep, Germany), where at least three pictures with approx. 1000 fibers per picture were evaluated. From this, the weight lengthed average was calculated as fibre length.

\section{Conclusion}

A process was developed that enables recycling of carbon fiber composites so that they do not have to be disposed of in landfills. By using a pyrolysis approach the polymer matrix is transferred into energy and the carbon fibers can be regained. At a pyrolysis temperature of $560^{\circ} \mathrm{C}$ carbon fibers with good surface properties and a total carbon content of $87.4 \%$ could be obtained. The reusability of the recycled carbon fibres could be demonstrated by compounding with polyamide. The lower calorific value of the pyrolysis vapor is $26.3 \mathrm{MJ} \cdot \mathrm{kg}^{-1}$ at a reaction temperature of $560^{\circ} \mathrm{C}$. The total heat requirement for the pyrolysis of 
CFC preprags is $1.6 \mathrm{MJ} \cdot \mathrm{kg}^{-1}$ at a pyrolysis temperature of $560^{\circ} \mathrm{C}$. Aromatic compounds and phenol derivatives could be detected in pyrolysis vapor that was burned in order to create thermal energy. The $\mathrm{rCF}$ were used to reinforce PA6 again, the yielded mechanical properties are reduced in comparison to vCF due to the lack of interaction at the surface. Therefore, future investigations should look into the effects of further fiber surface treatments and how to apply these to rCF as this will have a beneficial effect not only for polymide matrix but also other polymers.

\section{Conflicts of Interest}

The authors declare no conflicts of interest regarding the publication of this paper.

\section{References}

[1] Yatim, N.M., Shamsudin, Z., Shaaban, A., Ghafar, J.A. and Khan, M.J.H. (2020) Recovery of Carbon Fiber from Carbon Fiber Reinforced Polymer Waste via Pyrolysis. Journal of Advanced Manufactoring Technology, 14, 37-47.

[2] Giorgini, L., Benelli, T., Mazzocchetti, L., Leonardi, C., Zattini, G., Minak, G., Dolcini, E., Tosi, C. and Montanari, I. (2014) Pyrolysis as a Way to Close a CFRC Life Cycle: Carbon Fibers Recovery and Their Use as Feedstock for a New Composite Production. Proceedings of the 7 th International Conference on Times of Polymers ( TOP) and Composites, Ischia, Italy, 22-26 June 2014, 354-357. https://doi.org/10.1063/1.4876851

[3] Giorgini, L., Benelli, T., Mazzocchetti, L., Leonardi, C., Zattini, G., Minak, G., Dolcini, E., Cavazzoni, M., Montanari, I. and Tosi, C. (2015) Recovery of Carbon Fibers from Cured and Uncured Carbon Fiber Reinforced Composites Wastes and Their Use as Feedstock for a New Composite Production. Polymer Composites, 36, 1084-1095. https://doi.org/10.1002/pc.23440

[4] Ma, C., Sánchez-Rodríguez, D. and Kamo, T. (2020) Influence of Thermal Treatment on the Properties of Carbon Fiber Reinforced Plastics under Various Conditions. Polymer Degradation and Stability, 178, Article ID: 109199. https://doi.org/10.1016/j.polymdegradstab.2020.109199

[5] Yang, J., Liu, J., Liu, W., Wang, J. and Tang, T. (2015) Recycling of Carbon Fibre Reinforced Epoxy Resin Composites under Various Oxygen Concentrations in $\mathrm{Ni}$ trogen-Oxygen Atmosphere. Journal of Analytical and Applied Pyrolysis, 112, 253-261. https://doi.org/10.1016/j.jaap.2015.01.017

[6] Nahil, M.A. and Williams, P.T. (2011) Recycling of Carbon Fibre Reinforced Polymeric Waste for the Production of Activated Carbon Fibres. Journal of Analytical and Applied Pyrolysis, 91, 67-75. https://doi.org/10.1016/j.jaap.2011.01.005

[7] Witik, R.A., Teuscher, R., Michaud, V., Ludwig, C. and Månson, J.-A.E. (2013) Carbon Fibre Reinforced Composite Waste: An Environmental Assessment of Recycling, Energy Recovery and Landfilling. Composites Part A: Applied Science and Manufacturing, 49, 89-99. https://doi.org/10.1016/j.compositesa.2013.02.009

[8] Meyer, L.O., Schulte, K. and Grove-Nielsen, E. (2009) CFRP-Recycling Following a Pyrolysis Route: Process Optimization and Potentials. Journal of Composite Materials, 43, 1121-1132. https://doi.org/10.1177/0021998308097737

[9] Hengstermann, M., Raithel, N., Abdkader, A., Hasan, M.M.B. and Cherif, C. (2015) 
Development of New Hybrid Yarn Construction from Recycled Carbon Fibers for High Performance Composites. Part-I: Basic Processing of Hybrid Carbon Fiber/Polyamide 6 Yarn Spinning from Virgin Carbon Fiber Staple Fibers. Textile Research Journal, 86, 1307-1317. https://doi.org/10.1177/0040517515612363

[10] Feng, N., Wang, X. and Wu, D. (2013) Surface Modification of Recycled Carbon Fiber and Its Reinforcement Effect on Nylon 6 Composites, Mechanical Properties, Morphology and Crystallization Behaviors, Current Applied Physics, 13, 2038-2050. https://doi.org/10.1016/j.cap.2013.09.009

[11] Faruk, O., KC, B., Tjong, J. and Sain, M. (2017) Automotive Prototype from Recycled Carbon Fiber Reinforced Recycled Polyamide Composite.

[12] Thomason, J.L. (2001) Micromechanical Parameters from Macromechanical Measurements on Glass Reinforced Polyamide 6,6. Composites Science and Technology, 61, 2007-2016. https://doi.org/10.1016/S0266-3538(01)00062-8 